\title{
Large-Scale Co-generation of Electricity and Hydrogen by Uranium, Thorium and Solar High Temperature
}

\section{Energy}

\author{
Urban Cleve \\ Consultant High Temperature Technology, Krupp Reaktorbau GmbH, Hohenfriedbergerstr.4, Dortmund, D-44141, Germany
}

\begin{abstract}
Hydrogen production is one of the most important tasks for developing worldwide non-industrial regions. The evaporation of sea/wastewater and following condensing will be the very best technology but with the highest costs for heating up. HTR-power stations are the utmost technology to solve the cost factor due to producing high temperature heat together with electric power for all secondary processes by minimizing costs for every secondary production line. The additional use of sun power may enlarge the profitability of HTR-power plants with combined generation of electricity and hydrogen and/or drinking water.
\end{abstract}

Key words: Nuclear, uranium, thorium, sun power, hydrogen, drinking water.

\section{Introduction}

Hydrogen is a clean energy without $\mathrm{CO}_{2}$-emissions when used in trucks, busses and gasoline driven vehicles.

The production of hydrogen to minimize gas emissions, mainly by vehicles, is the most important task to reach economic energy and worldwide political goals by reducing $\mathrm{CO}_{2}, \mathrm{NO}_{x}$ and $\mathrm{SO}_{2}[1,2]$.

Hydrogen can only be produced by use of electricity and very high temperatures. As primary energy, only carbon content materials can be used resulting in carbon dioxide emissions.

It is also possible by using renewable energies, however, they have the disadvantage that they can only be used with interruption in changes of daily and seasonal periods. To reach a continuous production process, it is necessary to store large quantities of produced energy. This can only be accomplished with extraordinarily high costs and large losses of energy. Energy losses will always be changed to heat into the environment.

Corresponding author: Urban Cleve, consultant of high temperature technology.
Large technical production of hydrogen is only possible by electric energy produced in large power stations by burning fossil fuels such as coal, gas and oil. The consequences are very high losses of heat. The heat content of the produced hydrogen is much lower than it is in the primary energy. The same problem occurs by the use of e-vehicles (Fig. 1).

The heat content of all used primary energy fossil fuels is by far larger than the heat powered in fossil driven vehicles as they need more primary energy. In consequence, the worldwide reserve stocks of primary energy will be reduced more quickly to the disadvantage of future generations. The production of heat and electricity by nuclear power can avoid this.

They have no $\mathrm{CO}_{2}$-emissions, but there is no fissile uranium for a longtime reserve.

Uranium breeder technology is the only method to solve these problems by breeding thorium up to fissile uranium. This has been proven with the AVR and THTR-300 nuclear power stations. Thorium technology can only be operated in TVHT-reactors.

Very high temperatures of over $1,000{ }^{\circ} \mathrm{C}$ are necessary for large scale production of hydrogen energy. The AVR reactor [3] is the only reactor which was operated 


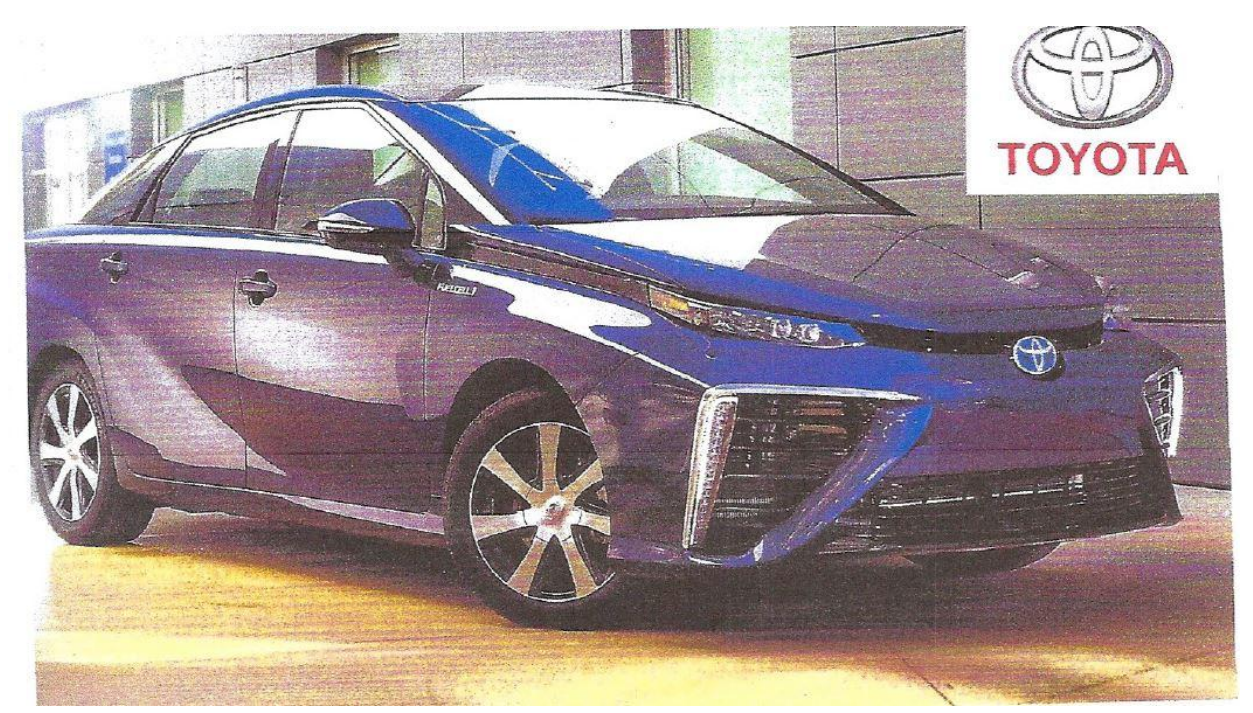

Fig. 1 Toyota hydrogen driven car.

at $950-1,000{ }^{\circ} \mathrm{C}$. By using ceramic structure materials such as a graphite and carbon stone, the helium primary gas temperature may be as high as $1,200{ }^{\circ} \mathrm{C}$. The limiting factor of very high temperatures by rising decay heat is the "loss of coolant accident". The limited temperature of the pebble fuel elements must not exceed $1,620{ }^{\circ} \mathrm{C}$ and depends on the design of the pebble bed core.

The temperature outside the inner portion of the reactor is limited by the stresses of the connecting pipes [6].

Only with the German AVR and THTR-300 we have up to now experiences with high temperature operated nuclear power stations.

\section{Using TVHTR-Technology to Generate High Temperature Energy without Any Nuclear Risks}

As a young engineer in the power plant department with Brown Boveri, Dr. Schulten had the idea to design nuclear power stations without major risk to the environment or population. He determined that the following requirements must be met to accomplish this $[3,4]$.

- The negative nuclear temperature coefficient must avoid a maximum credible accident (MCA).

- Ceramic fuel elements must bear high temperatures in operation and accidents without any damage. A homogenous mixture of nuclear fuel and graphite should be able to use different fissile and breeding fuel without the danger of a chain reaction or too high of a temperature and pressure increase.

- The resultant nuclear heat shall be the basis for numerous variations including the production of electrical energy, drinking water and hydrogen.

- The world's energy industries need safe, simple and economical nuclear power plants which could be constructed in developing countries.

These overarching views in nuclear and design concepts led to the first worldwide pebble bed reactor, the AVR.

Schulten's vision can only be compared with that of Wernher von Braun in the field of space travel.

The goal is to develop a nuclear technology with exceptional safety considerations:

- there can not be any nuclear risk;

- no nuclear or design rest-risk;

- safety considerations are deemed to be more important than economical considerations.

These goals can be attained by:

- extensive nuclear physics calculations;

- the development of extremely safe fuel elements;

- the overall safe design of the entire nuclear plant and all components. 


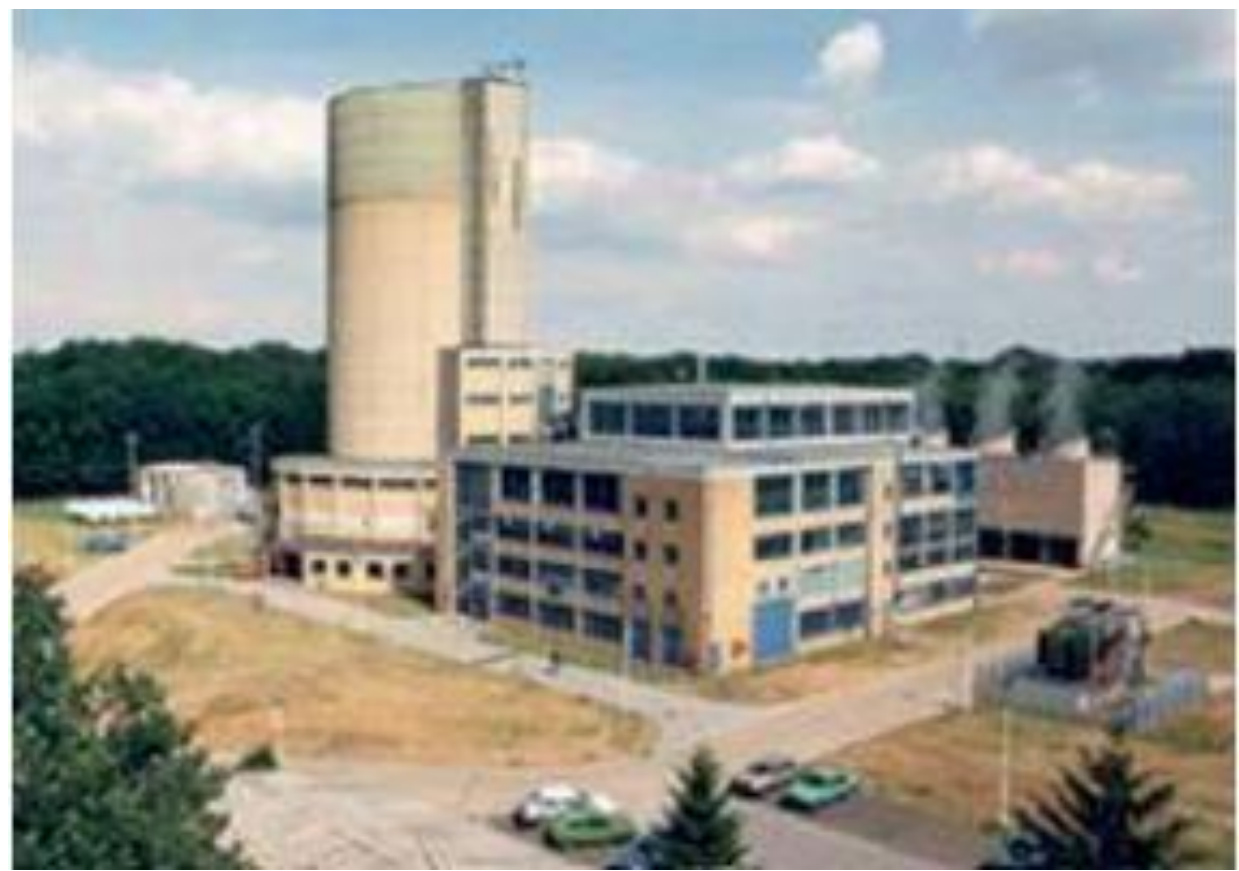

Fig. 2 The AVR 46 MWth/15 MWel experimental HTR power plant.

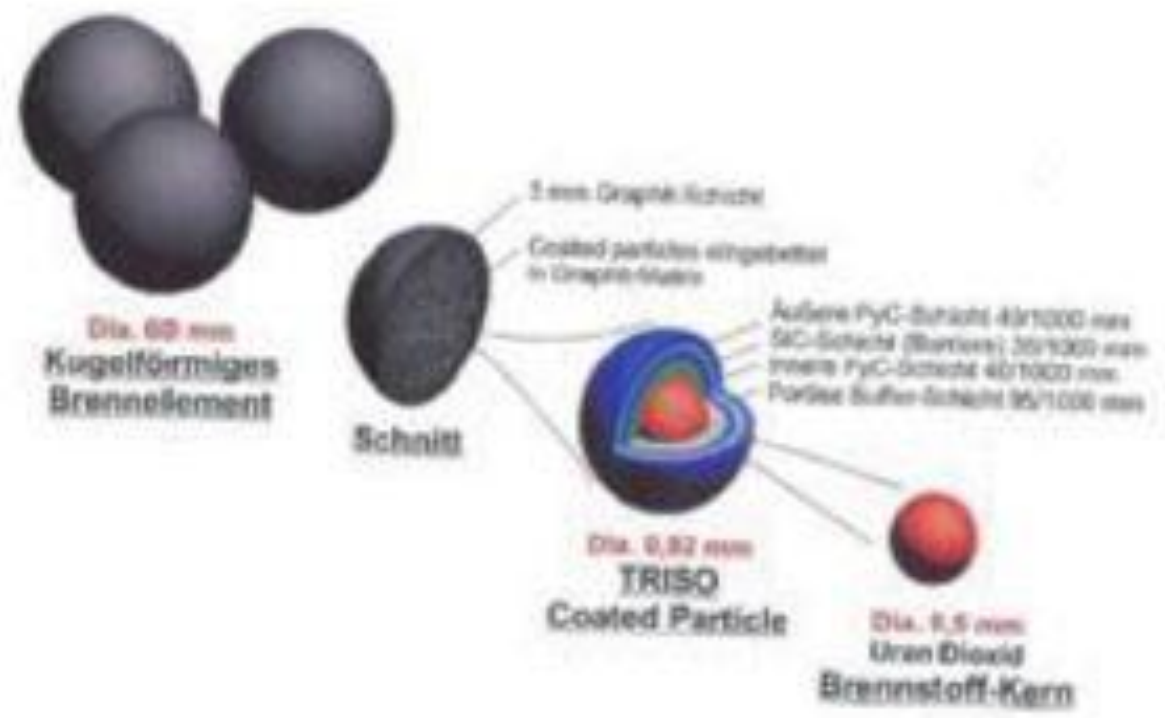

Fig. 3 Composition of a TRISO-pebble.

The most important component of every nuclear power station is the fuel elements.

- New pebble elements must be treated and stored inside and outside the reactor system by hand.

- The nuclear materiel must be enclosed within a gastight layer.

- Each pebble has a diameter of $60 \mathrm{~mm}$ and about 15,000 coated nuclear particles with a diameter of 0.5 mm enclosed within (Fig. 3).

- Each particle has three gastight layers that are able to prevent the emission of dangerous fissile products into the primary helium gas and after burning down to the environment.

- A total loss of all primary cooling helium gas into the environment must not lead to unacceptably high pollution. 
- The fuel particles of Thorium 232, Uranium 233/235/238, and Plutonium 238-243 can be used.

- All fission products are safely stored within the interior of the coating after extraction of the core during transport and storage to prevent any danger to the personnel or the environment.

- The nuclear activity of the AVR core was first calculated with 7,000,000 Curie. During operation of the power station with the newly developed Triso coated fuel elements, the radioactivity was measured at only 360 Curie.

Thorium can be used as a breeding material allowing the reactor to be operated as a breeding reactor [12].

- The fuel elements produce no decay heat and a facility to remove the decay heat is unnecessary.

These goals had been achieved through large international cooperation to develop fuel elements with Triso coating. This fuel can only be operated in graphite moderated high temperature nuclear power stations.

\section{Operational Experiences of the HTR-KKW AVR Juelich and THTR-300 Hamm}

Operational experiences with the HTR-KKW
AVR and the demonstration of KKW THTR-300 (Figs. 2, 4 and 11), are described in numerous publications [3-5].

\subsection{Operational Experiences with the AVR Juelich}

- The AVR was placed into operation in 1967 and shut down due to governmental order in 1989.

- At this time it reached an average operational time of $66.4 \%$.

- The maximum operational time was $92 \%$ and was comparable to other nuclear power stations that had been in service for a longer time.

- The AVR set a world record for a new power station design.

- No release of radioactive material occurred and neither the personnel nor the environment had been polluted.

- The graphite construction was a first in the world and 22 years of operation which showed not the slightest indication of damage or movement.

- The fuel charging unit for the pebbles operated without any problems and 2,400,000 pebbles had been moved. Only 220 crushed pebbles had been taken out of the circuit resulting in $99.999 \%$ efficiency.

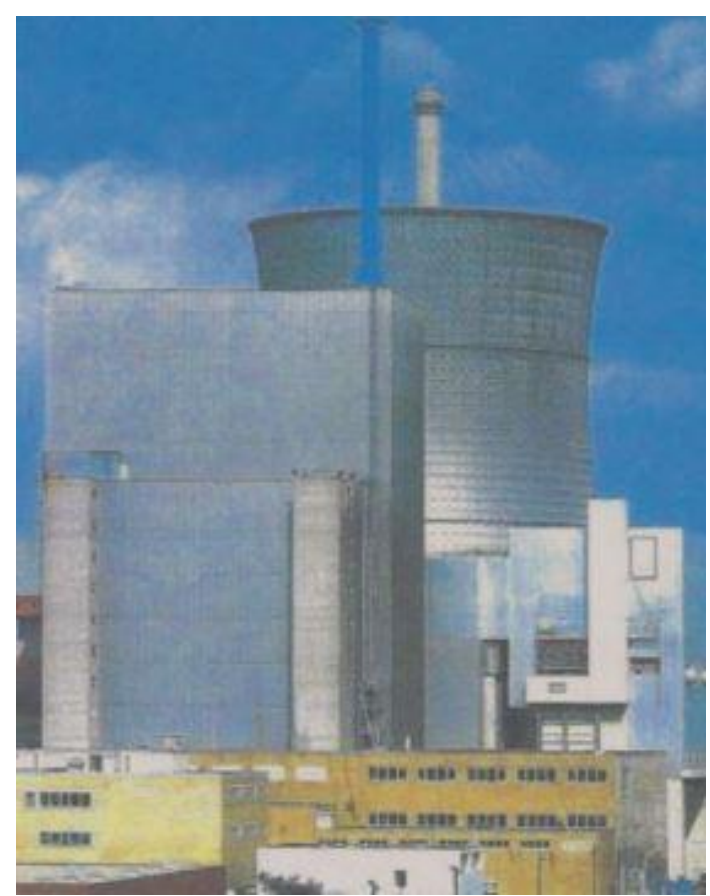

Fig. 4 THTR-300 MWel/750MWth demonstration power station. 
- According to the INES scale only one incident occurred with "1" and all the other events had an INES level of "zero" during 23 years of operation.

- An exceptional and symmetrical flow of the helium cooling gas was reached in the pebble bed and the steam generator.

- New fuel pebbles could be handed and stored by hand without any danger of pollution.

- Nearly all newly developed components worked without additional problems.

\subsection{Operational Experiences with the THTR-300 [5]}

The design changes of the THTR-300 versus AVR are:

- a newly developed pre-stressed concrete pressure vessel instead of two steel pressure vessels;

- larger diameter and higher core;

- insertion of the shut-down rods into the pebble bed, only the regulation rods remained in the reflector;
- the fuel element extraction device and the inner graphite wall design were modified;

- helium flow through the pebble bed was directed downward instead of upward.

The decision to insert the shut-down rods into the pebble bed was a serious mistake causing a large number of ruptured pebbles. This decision was made because the diameter of the pebble bed showed to be too large, which means "mighty". At this time we had no experience with the behavior of the graphite core construction and the alternative design using a ring-core (Fig. 5) which had been determined to be too dangerous at that time of exciting experiences.

Ultimately, there were several operational interruptions combined with too many damaged fuel elements resulting in higher operational costs. There was no danger of radioactive pollution even though the fuel elements were damaged. Despite these design problems and a significantly lower operational time,

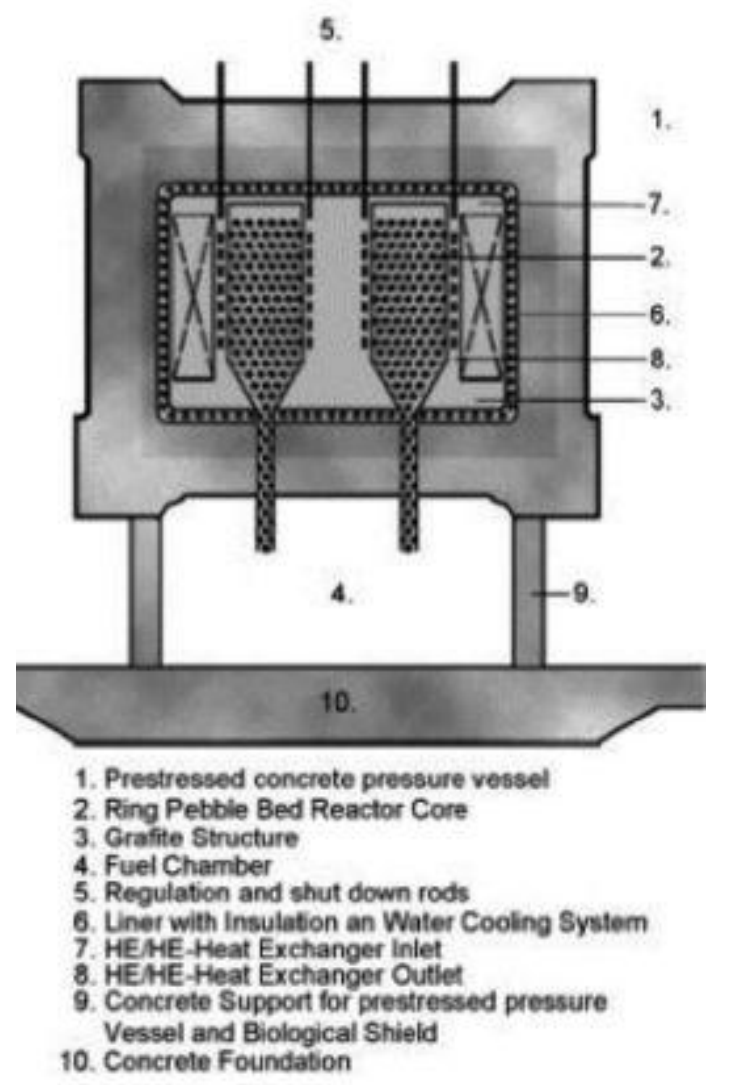

Fig. 5 Concept of pebble bed ring core. 


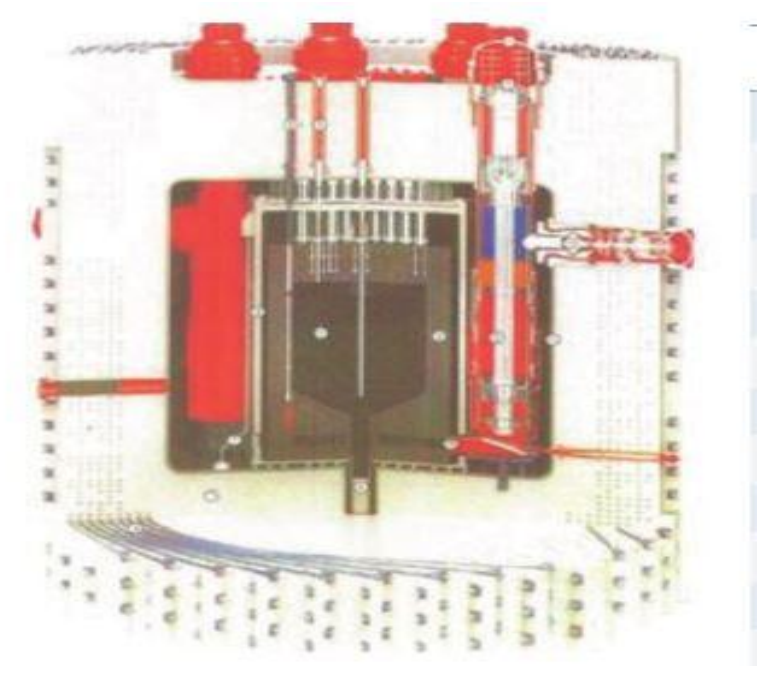

Fig. 6 Pre-stressed concrete pressure vessel and THRT-300 core.

the THTR-300 was able to reach the following significant capabilities.

- The newly developed pre-stressed concrete pressure vessel showed to be a key design choice for HTR-reactors due to safety reasons (Fig. 6).

$>$ Safe against airplane crashes.

Safe against political reasons.

Safe against air ingress.

Safe against every type of potential rupture and loss of primary helium gas.

Safe against the highest magnitude of earthquake;

Safe against possibility of cracks.

The steam generators worked without the slightest of problems.

The oil lubricated helium gas blowers demonstrated no risks at all.

- The reactor proved to have stable regulation possibilities from low power up to full and was able to maintain the regulation of net-frequency.

- The helium cooling gas flow from bottom upwards as in the AVR proved better than the downward flow.

- The graphite wall design of the AVR was much better than that of the THTR-300.

- The newly designed extraction device for the fuel pebbles performed more poorly than the AVR.

The results of the design changes proved to be worse than the AVR:
The consequence was a far worse pebble flow through the pebble bed. An HTR-core must not be too "mighty", meaning too large of a core diameter and height of the bed. The core of the AVR showed to have excellent core dimensions. These dimensions for high capacities of HTR-power station can only be reached with a ring-core design. The "mighty" of the core is of high importance for reaching low temperatures of the fuel pebbles in case of a loss of coolant accident and an MCA.

Together with Prof. Dr. Rudolf Schulten, it was agreed to perform the first simulated MCA test in a nuclear power station in the spring of 1967.

\section{Development and Functional Tests of Main Components [3, 4]}

\subsection{Prestressed Concrete Pressure Vessel}

Extensive pressure tests were performed in a laboratory using a 1:20 scale model of a pre-stressed concrete pressure vessel. The vessel was pressurized to nearly 200 bars with warm water.

The results are:

- no cables had been damaged;

- small cracks were noticed under high pressure and after repressuring the concrete was tight.

The results of the pressure tests enabled the development of calculations to be used when testing a 


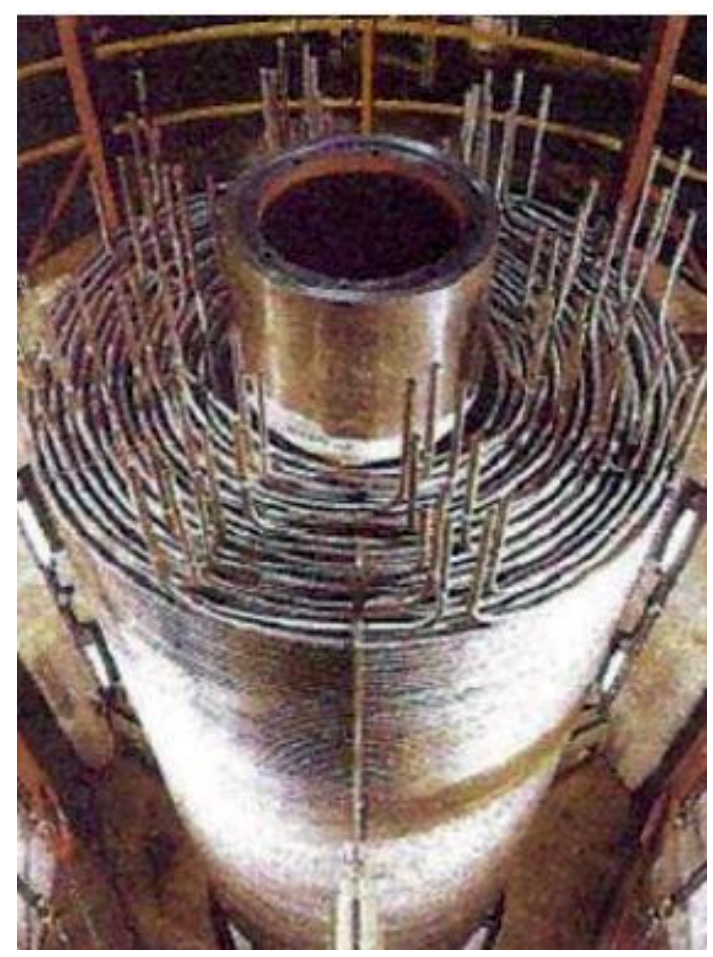

Fig. 7 Manufacturing of the THTR steam generator.

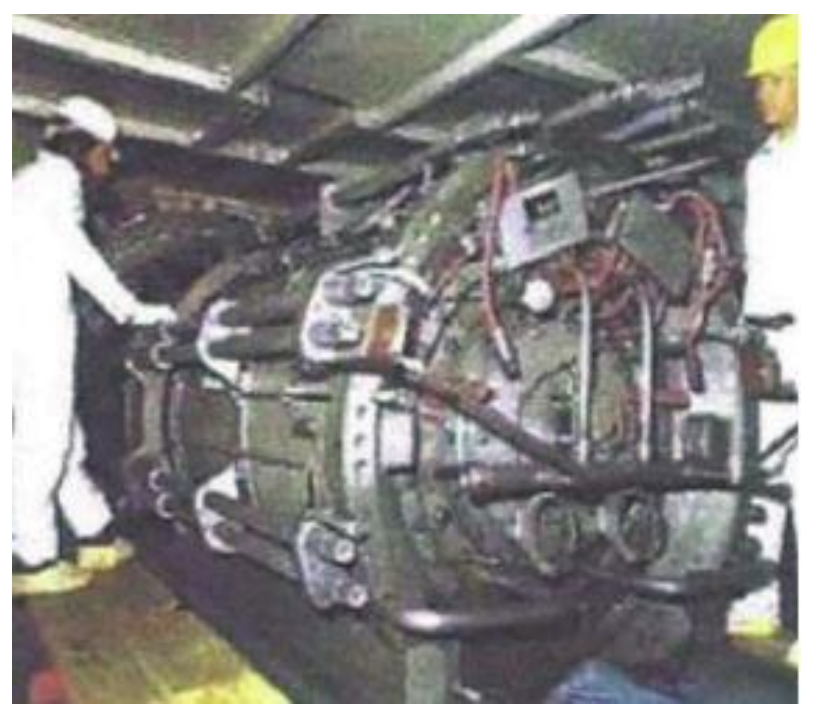

Fig. 8 Helium blower of THTR-300.

larger PCPV. The pressure tests of the PCPV of the HTR-300 indicated the calculations were very precise (Fig. 9).

\subsection{Cooling Gas Blowers}

The oil lubricated blowers (Fig. 8), two in the AVR and six in the THTR-300, functioned without any problems.

\subsection{Shut Down and Regulation Rods}

- The shut down rods of the AVR had been tested for years in the laboratory of BBC/Krupp, no problems occurred. After installing into the reactor and being tested under helium conditions they failed completely. They were redesigned and worked without any problems.

- The insertion of the shut down rods into the 


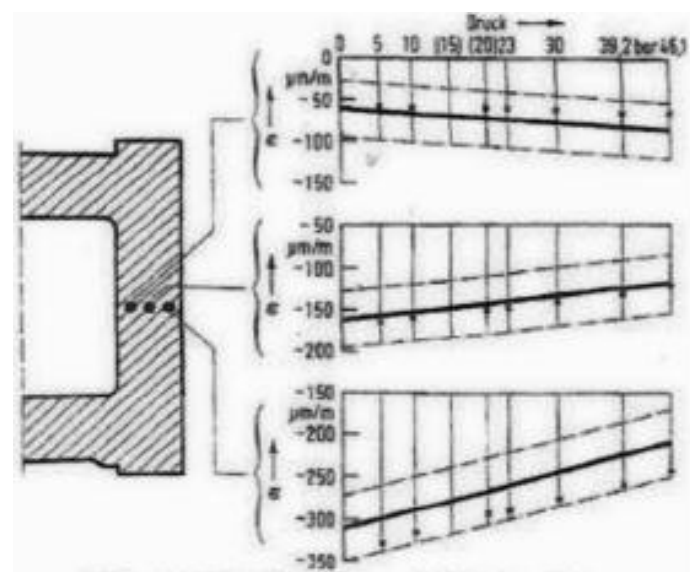

Dehnungen in vertikaler Richraeg Soll/fn-Vergleich
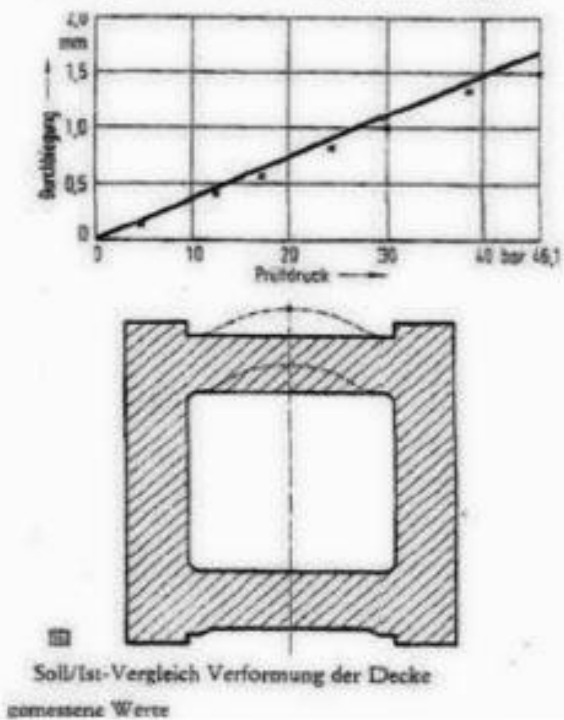

Fig. 9 Results of pressure test of the THTR-PCPV.

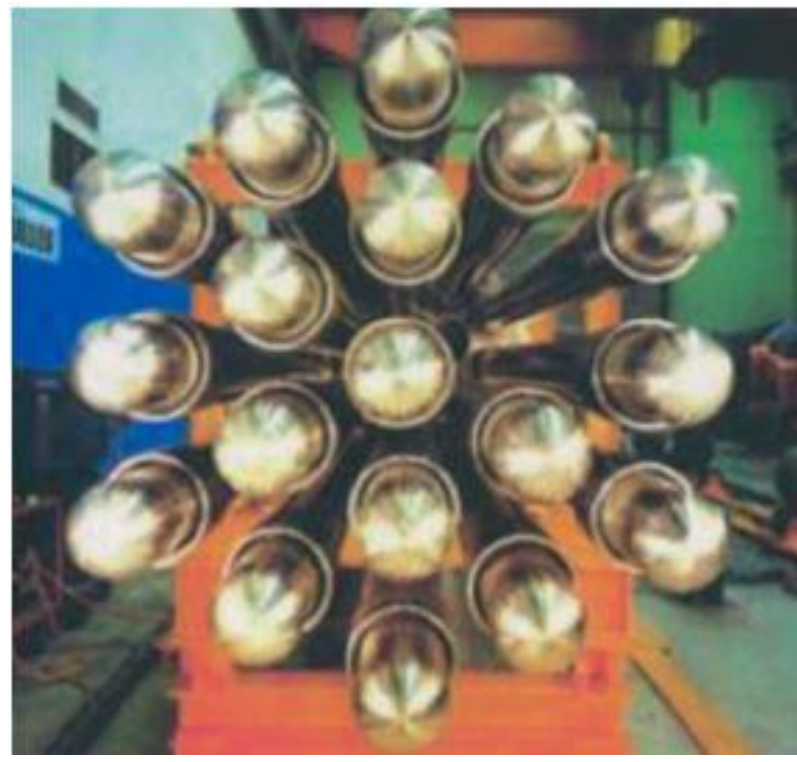

Fig. 10 Test facility of He-He heat exchangers in FZ-Juelich laboratory. 
pebble bed of the THTR discovered late was a mistake. About $0.6 \%$ of the pebbles ruptured, which was substantially higher when compared to the results of the AVR at $0.0092 \%$.

- The regulation rods were installed and guided into the graphite reflector and worked without any problems. This design can be installed in future ring core designs as regulation and shut down rods similar to the AVR design.

\subsection{Helium Valves}

All valves of the helium circuits were tested under normal conditions and were delivered by experienced suppliers. Under helium conditions they failed completely and had to be newly designed by BBC/Krupp engineers. Upon testing in a helium atmosphere they worked very well. The valves were a special design for the nuclear power plants without assistance of normal suppliers.

\subsection{Helium/pri > Helium/sec Heat Exchangers and Steam Generators [6]}

During manufacturing of the steam generators for the AVR it was necessary to develop new test instruments and new documents for the tube material (Figs. 7 and 10). The generators were manufactured on the job site. Pressure and tightness tests were successfully performed with helium. They were designed with an interlocking system. It was a very difficult solution and it was decided to design the THTR-300 steam generator as a tube-winding design which is proved to be a good decision. Both designs of the steam generator worked very well with no problems. Capacity, steam pressure, temperature, and the intermediate steam data were successfully achieved.

\section{Operation Tests for Licensure by Regulatory Authorities [3, 4]}

The AVR with all components was a totally new design. No prior experience of proved designs in normal plants with normal atmosphere could be used due to the helium. Therefore, many technical questions could not be answered by previous experience. In discussions with the regulatory authorities several problems could not be answered, mainly those concerning the safety of the plant. This led to an agreement to prove all of the unanswered technical questions through an MCA test in order to prove the inherent safety of the AVR. An MCA test had never before been conducted in a nuclear power station. Without this test the authorities would not be able to prove the operational safety and in consequence, the allowance to operate the AVR could not be approved.

Only after performing new safety calculations showing the thermal behavior of the core in case of total loss of coolant by decay heat it was decided to undergo this experiment.

All safety components had to be blocked and the entire power station had to be without electricity. Only the temperature of the core would be measured. Prior to performing this experiment safely all safety devices were tested by our engineers. This was reached perfectly.

The MCA test was conducted in the spring of 1967 early in the morning with a quick stop of the plant. At the start of the test, we had full power of $45 \mathrm{MWth}$ and core temperature of $850{ }^{\circ} \mathrm{C}$. All cooling water pumps, blowers, reserve diesel engines were out of operation and the safety rods were blocked. The test conditions were more complicated than that they had been with the Chernobyl and Fukushima reactors MCA.

The behaviour of the temperature after quick stop was nearly as foreseen and calculated in the safety analyses. After two hours the temperature showed the calculated maximum of nearly $1,200{ }^{\circ} \mathrm{C}$ and after that peak the temperature began to decrease. The allowed critical temperature of $1,620{ }^{\circ} \mathrm{C}$, was far from being reached and at midnight the full success of this dangerous experiment was apparent. All conditions of the regulatory authorities had been fulfilled.

This was the first MCA experiment in the history of 
large nuclear power stations. A few days later the AVR was restarted without any problems and the Technical Inspection Association (TÜV) confirmed the full power approval for the AVR.

This test was renewed 10 years later as an experiment to prove and reconfirm all calculations to initiate a safety analysis program for calculations of future larger pebble bed reactors.

\section{Safety Requirements for High-Temperature Nuclear Power Stations}

The German Ministry for Nuclear Safety, BMFT, had been invited to a fundamental discussion concerning the safety of nuclear power stations held at KIT Technical University of Karlsruhe. The following basic requirements, fixed by Prof. Dr. K. Kugeler, former member of the German RSK, were discussed:

- safe against cracking of the pressure vessel;

- independent reduction of decay heat;

- core must have a negative temperature coefficient;

- safe against earthquakes and tsunamis of the highest magnitude;

- zero emission under all circumstances, such as cyber attacks or political disturbances.

It was decided that these demands can only be realized with fuel elements having Triso-coated fuel particles together with a pre-stressed concrete pressure vessel.

\section{Combination of TVHTR-KKW with Solar Plants to Produce Clean Water and Hydrogen}

The design of a large TVHTR-PS was described in several presentations and is based on the concept of the German THTR-300 together with the operational experiences of the AVR [3-5].

The combination of both plants shall have the following parts:

- high pressure and temperature turbine generator set with intermediate reheating of the steam;

- steam temperature $>530{ }^{\circ} \mathrm{C}$, steam pressure $>220$ bar, reheating $>530{ }^{\circ} \mathrm{C}$;

- multiple steam extractions to heat up the water of the thermodynamic process and the desalination plant;

- condensers to cool the exhaust steam;

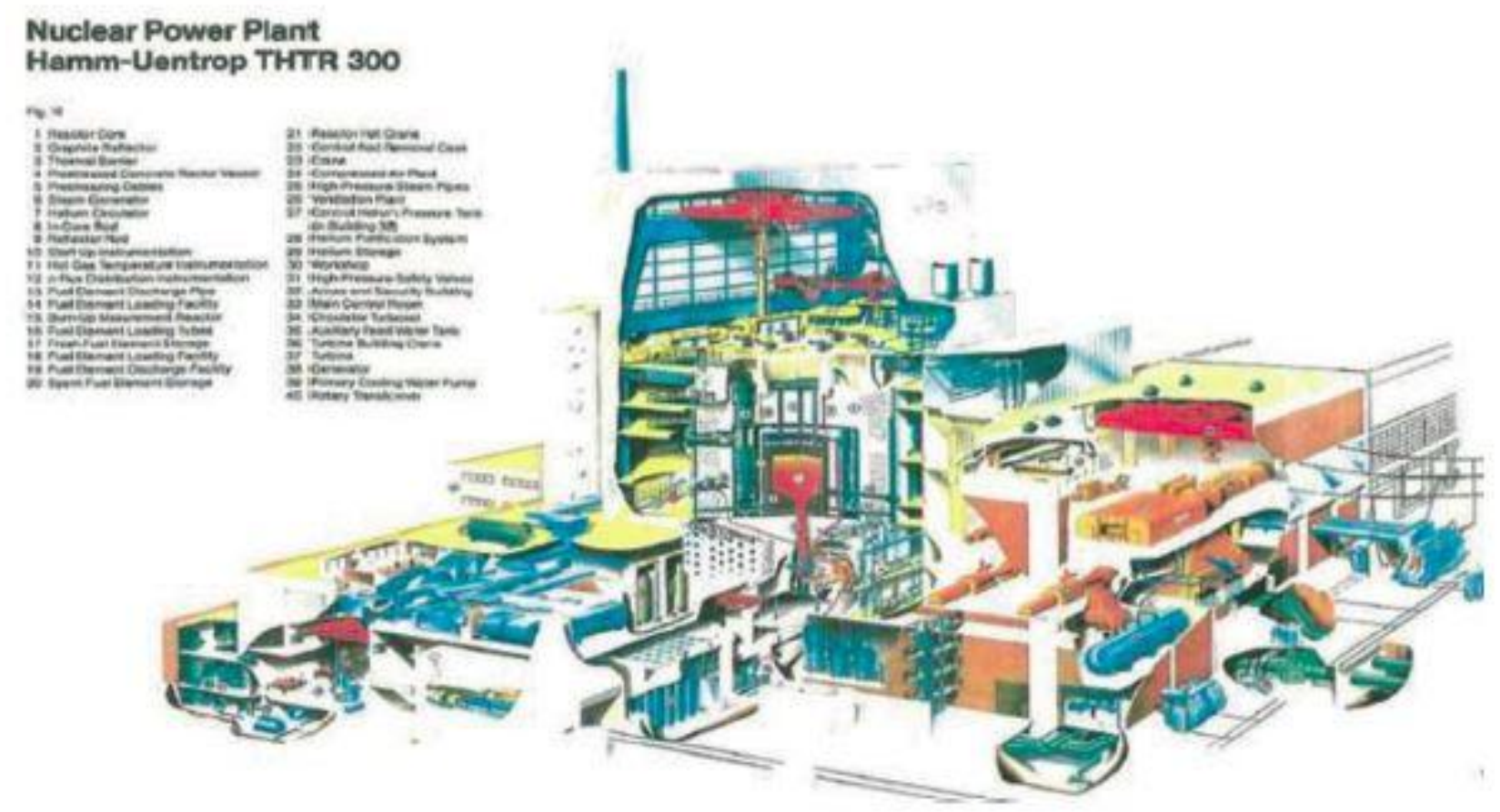

Fig. 11 Survey of the THTR-300. 
- solar plant with solar collectors and heat transport medium;

- the hydrogen plant will be served with the required heat, which means steam with the necessary temperature and pressure.

The production of clean water by water intake is with the following steps:

- seawater intake by pumps and pre-cleaning;

- first warm-up stage in the turbine condenser;

- second warm-up stage by solar energy in the heat exchanger;

- final warm-up by low pressure steam from the power turbine;

- the condensed water is returned to the steam turbine thermodynamic circuit;

- the clean water will be first stored in water tanks to ensure a continual production process for electricity and hydrogen $[9,10]$.

Technical and economical criteria are as follows.

- The water is in the first warm-up stage and is used as cooling water for the exhaust steam of the turbine. No cooling tower or a smaller tower may be necessary. The temperature rise may be 15 to $30^{\circ} \mathrm{C}$ and is only an economical question. The lower the temperature rise, the higher the efficiency of the thermodynamic circuit.

- The heat production of the solar plant varies between daily and seasonal changes. In times of less heat production the quantity of exhaust low pressure steam of the turbine varies in the same degree. The unused exhaust steam will be extended into the condenser.

- So it is possible to produce electrical energy indirectly.

- The turbine generator set is able to take part in the net regulation.

- The capacity range for electricity and hydrogen production can be modified.

- The possible capacities of the TVHT reactors may start with 40 MWth up to 100 MWth with the AVR concept. If very large capacities are required, the range of a pre-stressed concrete pressure vessel is up to greater than 4,000 MWth.

- It is possible to design power stations up to 1,200 $\mathrm{MWel} / \mathrm{h}$ and more than 4,000 MWth using digital computer-aided design (CAD) programs.

- This combination makes it possible to operate the hydrogen plant continuously without interruption.

With this combination, a large percentage of the total heat from the steam thermodynamic circuit can be used together with the additional heat from the solar plant. This combined process makes it possible to reach a thermodynamic efficiency of greater than $90 \%$.

\section{Large Scale Production Process for Coal Gasification and Hydrogen Production [7-9,} 11]

The basic for all hydrogen production processes is clean water.

The production of hydrogen itself can be realized by several different processes $[1,7,8]$.

Electricity from power stations, especially nuclear power, can separate water into hydrogen and oxygen by reverse osmosis (RO) plants. Only electric power is used.

Fore co-generation of electricity and very high nuclear heat General Atomics (GA) published the sulfur-iodine (S-I) process in its project 49009, sponsored by the US Department of Energy [8] with the objective to define an economically feasible concept for production of hydrogen by nuclear power, using an advanced high temperature nuclear reactor source. Selected was the sulfur-iodine-cycle.

This S-I thermochemical water splitting cycle (Figs. 12 and 13) is well suited for hydrogen production by nuclear energy. The required heat of $800{ }^{\circ} \mathrm{C}$ is produced in the VHT-pebble bed reactor. The radioactive contaminated primary helium gas heat in the inner cycle is changed in the He/primary to clean $\mathrm{He} / \mathrm{sec}$ heat, situated in the inner concrete pressure vessel.

The heat of the clean helium is partly led to the heat exchanger in the S-I-cycle and exchanged into the 
$\mathrm{He} / \mathrm{H}_{2} \mathrm{SO}_{4}$ heat exchanger with $800{ }^{\circ} \mathrm{C}$.

The further produced high temperature heat feeds the steam-generator to produce steam and electricity in the turbine-generator-set.

The low temperature heat is extracted as exhaust steam from the low-pressure part of the turbines thermodynamic process.

"The sulfuric acid can be decomposed at about
$850{ }^{\circ} \mathrm{C}$ releasing the oxygen and recycling the sulfuric acid. The hydrogen iodine can be decomposed at about $400{ }^{\circ} \mathrm{C}$, releasing the hydrogen and recycling the iodine. The whole process takes in only clean water and high temperature heat and releases only hydrogen, oxygen an low temperature heat" [8], which can be recycled into the water thermodynamic process for heat together with electricity generation.

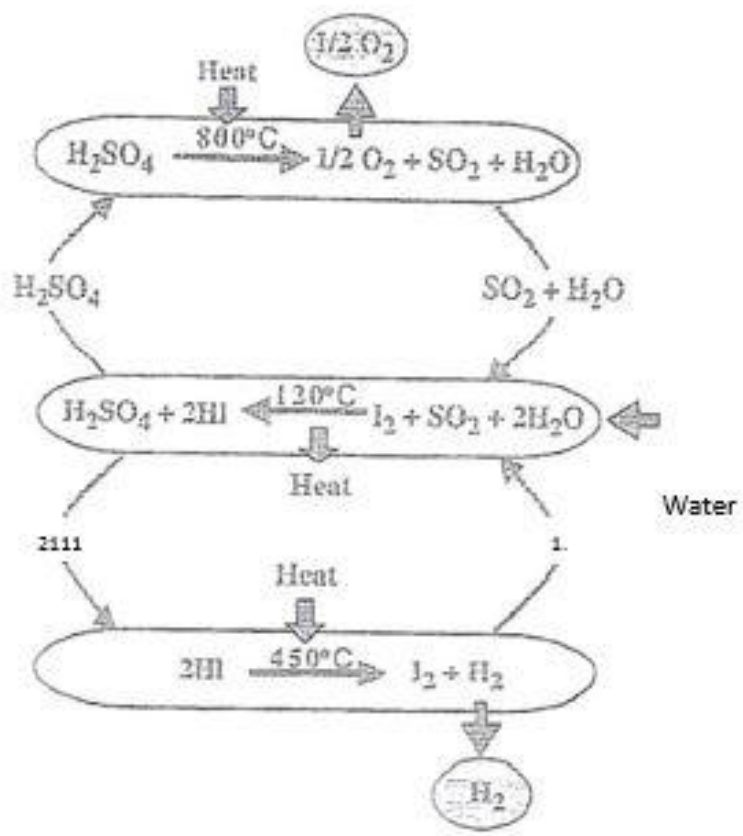

Fig. 12 The S-I thermochemical water-splitting cycle [8].

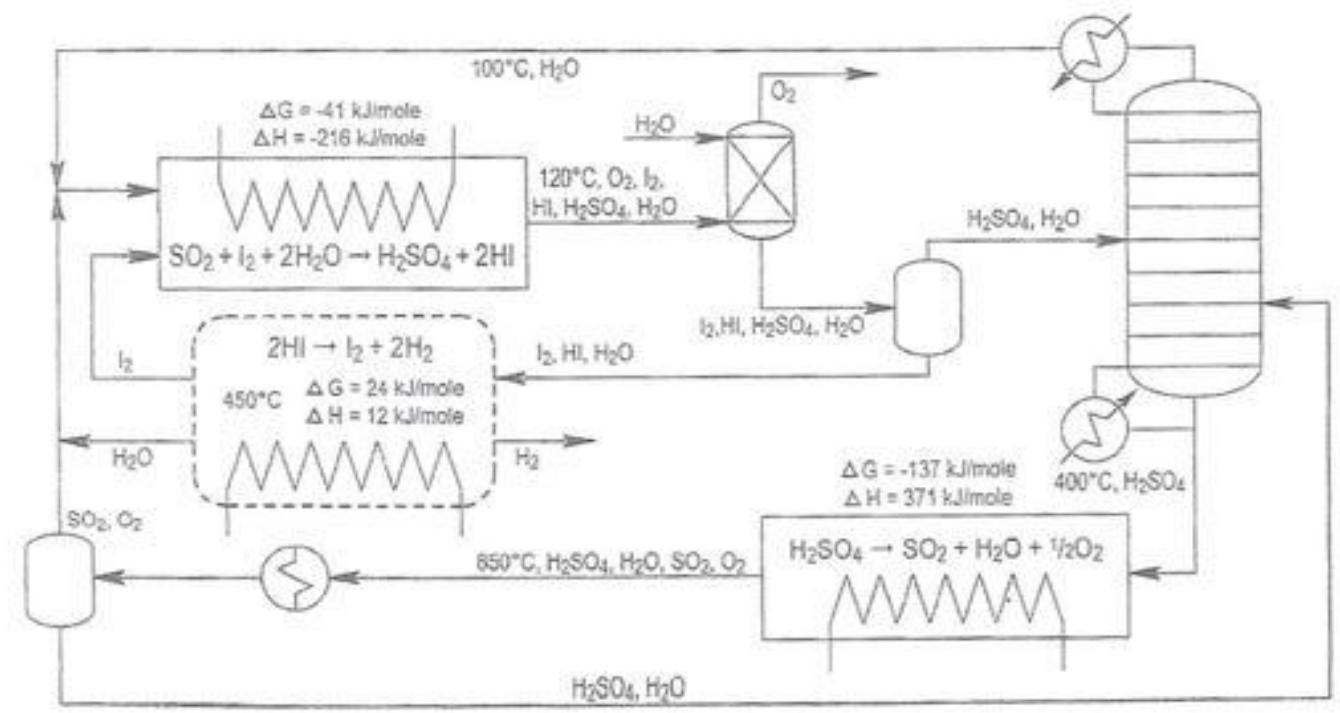

Fig. 13 S-I thermochemical water-splitting process schematic [8]. 


\section{Summary and State of Development}

Planning and design of hydrogen plants are well known technologies and no further developments may be necessary.

For the design of the nuclear reactor part, we have a great deal of experience from the design, experiments, and operational results of the AVR and THTR300. This experience would enable us to start a new combined plant immediately [11].

To begin, we would need to know the capacity of hydrogen, the amount of electricity production, and the location of the construction site. For initial designing all necessary design, nuclear physics, and thermodynamic calculation programs are available. The results of the first planning would simplify the approval of all necessary documents from the authorities. Experience has proven that this method will reduce future costs enormously.

All these experiences are known now. Now the preconditions are excellent. For the nuclear reactor part all former open questions are well-known today and the secondary parts for production of energy and hydrogen are conventional technology. With these plans we are able to complete an economical study concerning investment and operational production costs for electric energy and hydrogen.

The investment for such a study can be estimated between 15 and 20 million Euro.

Compared with well-known nuclear power stations, the PWR/BWR, LWR, and the TVHTR have numerous advantages:

- to substitute the fossil fuel primary energy sources, oil and gas;

- all pebbles can be circulated in the reactor continuously without interruption of operation;

- they can be recirculated to reach maximum burn-up;

- the production of the pebbles can be completed at a central plant to serve many different power stations in several countries;

- new fuel pebbles will only be delivered against exchange of the burnt down pebbles;

- reprocessing can be done in the same facility;

- the transportation from production facility to the power stations is without any nuclear risk;

- the Non-Proliferation Treaty (NPT) agreement can be kept under all circumstances;

- the thermodynamic circuit is much better due to the potential higher steam temperature and pressure;

- a combination with solar heat is easily possible;

- it is possible to convert useless thorium to breed fissile uranium $[12,13]$.

This design is a thermal breeding power station with the highest safety and very high efficiency.

\section{Reference}

[1] Schulien, S. "EinWeg aus der Abhängigkeit von Erdöl/Nutzbarmachung der Wasserstofftechnik.” FH Wiesbaden.

[2] Merkel, A. 1954. Dissertation zur Erlangung des Akademischen Grades eines Dr. rer. nat., Zentralinstitut flir Physikalische Chemie.

[3] Cleve, U. 2018. "The Technology of TVHTR-Nuclear-Power-Stations with Pebble Fuel Elements." ATW 63 (3).

[4] Cleve, U. 2017. "The Technology of TVHTR-Nuclear-Power-Stations with Pebble Fuel Elements to Generate 600 MWe1/1.500 MWth Electric Power and Heat to Produce Drinking Water out of Sea-Wastewater and/or Hydrogen in Combination with Solar Plants." Czech Hydrogen Days, Prague.

[5] Bäumer, R. 1989. “Ausgewählte Themen aus dem Betrieb des THTR-300." VGB Kraftwerkstechnik 69: 158-64.

[6] Guohui, S., et al. 2014. "Discussions of High Temperature Performance of Alloy 625 for HTR Steam Generators." In Proceedings of HTR, China.

[7] Neef, H. J., and Weisbrodt, I. 1979. "Coal Gasification with Heat from High Temperature Reactors." KFA Juelich.

[8] Schultz, K. R., Brown, L. C., Besenbruch, G. E., and Hamilton, C. J. 2003. Large Scale Production of Hydrogen by Nuclear Energy for the Hydrogen Economy. G. A. Project 49009.

[9] Lee, S., Yoo, Y. J., Kye, D. H., Heo, G., Jeon, E., and Park, S. 2018. "Heat Balance Analysis for Energy 


\section{Large-Scale Co-generation of Electricity and Hydrogen by Uranium,}

Thorium and Solar High Temperature Energy

Conversion Systems of VHTR." ATW 63 (4): 230-4.

[10] Zhang, Z. Y., Dong, Y. J., Li, F., et al. 2016. "The Shandong Shidao Bay 200 MWel High-Temperature Gas Cooled Reactor Pebble-Bed Module (HTR-PM) Demonstration Power Plant." Engineering 2 (1): 112-8.

[11] Cleve, U. 2018. "Co-generation of Electricity and Desalinated Sea/Wastewater by Uranium, Thorium and
Solar High Temperature Energy." Presented at IAEA/DME Seminar KWS Essen.

[12] Cleve, U. 2013. Breeding of Fissile Uranium Using Thorium with Pebble Fuel Elements. EIR-Conference Report 49, May 2013.

[13] Merkel, A. 1986. "Zukunftsdialog der Bundeskanzlerin: Wovon sollen wir leben? Thorium als Energeiquelle." 